\title{
MODELING OF LARGE DEFORMATED ELASTOMETRIC SLEEVE USING FINITE ELEMENT METHOD
}

\author{
Jan Amborski \\ Institute of Aviation \\ Al. Krakowska 110/114 \\ 02-256 WARSZAWA, \\ POLAND \\ j_amborski@yahoo.com
}

Keywords: simulation, fem, elastometrics.

\section{SUMMARY:}

The paper presents a method of hyperelastic materials analysis. For some time now Finite Element Method (FEM) software allows to calculate stress in this kind of materials, which make an engineering work easier. In the paper a comparison of quasianalytical method of behaviour modeling of elastometric sleeve is presented with the results obtained with use of FEM software and experimental results. Each FEM software offers a choice of large number of mathematical models of materials. The paper presents a comparison of eight hyperelastic material models and points out the best one for given material. All the calculations were made as a prediction of a vibration damper piston dimensions. The calculations were verified during experiments.

\section{QUASI ANALITICAL SOLUTION}

The first step to predict dimensions of a sleeve damper piston was quasi-analytical evaluation. Evaluation was made on the basics of Lame's problem and secant method. The Lame's problem assumes infinite tube, it means that all the stresses are only in radial and circumferential, the axial stresses are not taken into consideration (Eq. 1-4, Fig 1).

$$
\begin{gathered}
\sigma_{r}=\frac{E(\varepsilon)}{1-v^{2}}\left(\frac{d u}{d r}+v \frac{u}{r}\right), \\
\sigma_{t}=\frac{E(\varepsilon)}{1-v^{2}}\left(\frac{u}{r}+v \frac{d u}{d r}\right) . \\
u=C_{1} r+\frac{C_{2}}{r},
\end{gathered}
$$

$$
\sigma_{r}=\frac{E(\varepsilon)}{1-v^{2}}\left((1+v) C_{1}-(1-v) \frac{C_{2}}{r}\right)
$$

Where:

$$
\begin{aligned}
& \sigma_{\mathrm{r}}, \sigma_{\mathrm{t}}-\text { radial and circumferential stresses, } \\
& \mathrm{E}-\text { Young modulus, } \\
& v-\text { Poisson ratio, } \\
& \varepsilon-\text { strain, } \\
& \mathrm{u}-\text { displacement. }
\end{aligned}
$$

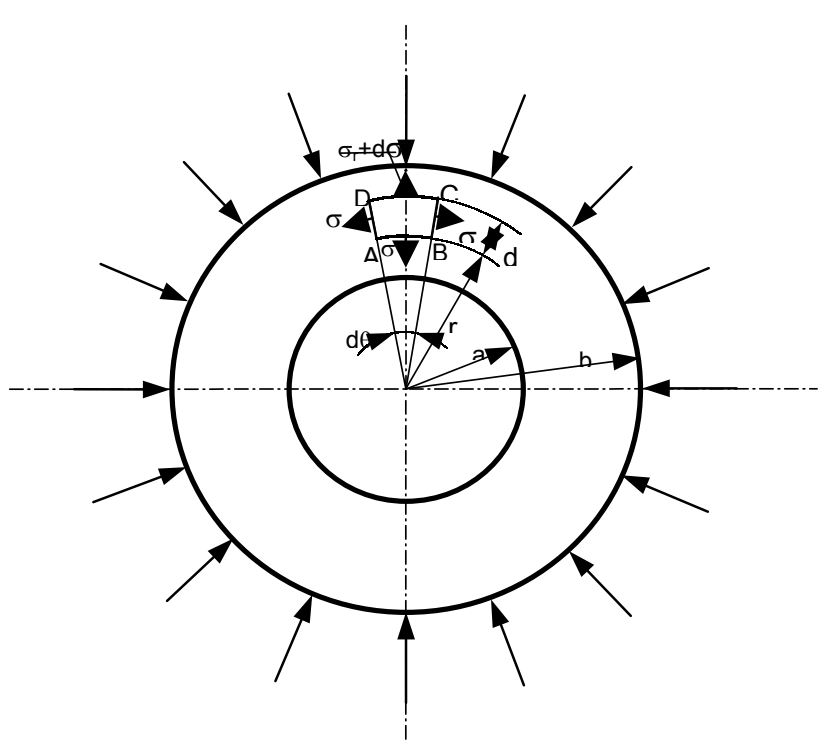

Fig. 1. A schema of Lame's problem.

In the original form of the Lame's problem a Young modulus was used as a constant, but in case of nonlinear material there was no such possibility. To point integral constants $\mathrm{C} 1$ and $\mathrm{C} 2$ and solve those equations a secant method was used. It is possible in the case when the border conditions are displacements. The 
solution of Lame's problem is given as Eq. 5.

$$
\sigma_{r}=\frac{E}{1-v^{2}}\left(\frac{\left(r_{c}-r_{t}\right)}{a^{2}-r_{t}^{2}}\right)\left(r_{t}(1+v)+\frac{r_{t} a^{2}}{r_{c}}(1-v)\right)
$$

where:

$$
\begin{aligned}
& r_{c}-\text { radius of cylinder } \\
& r_{t}-\text { radius of piston }
\end{aligned}
$$

To evaluate the axial force, the result was put into classic Coulomb friction equation:

$$
\sigma_{r} \cdot A \cdot \mu=F_{t}
$$

where:

$$
\begin{aligned}
& \text { A - surface of cylindrical part of piston, } \\
& \mu \text { - hypothetic friction coefficient } \\
& F_{t}-\text { axial force on the piston rod. }
\end{aligned}
$$

Those analyses give first estimate of interference for numerical solution.

\section{NUMERICAL SOLUTION}

The first step in numerical solution is a choice of mathematical model of the material. The software offers large number of the models. Eight of them were analyzed in several forms. There were Neo Hookean, Mooney-Rivlin, Polynomial, Blat-Ko, Ogden, ArudaBoyce, Yeoh and Gent models analyzed. The best one was a 5 parameter Moonney-Rivlin model. An example of not a proper model is shown on Fig. 3, whereas Fig. 4 presents the Mooney model.

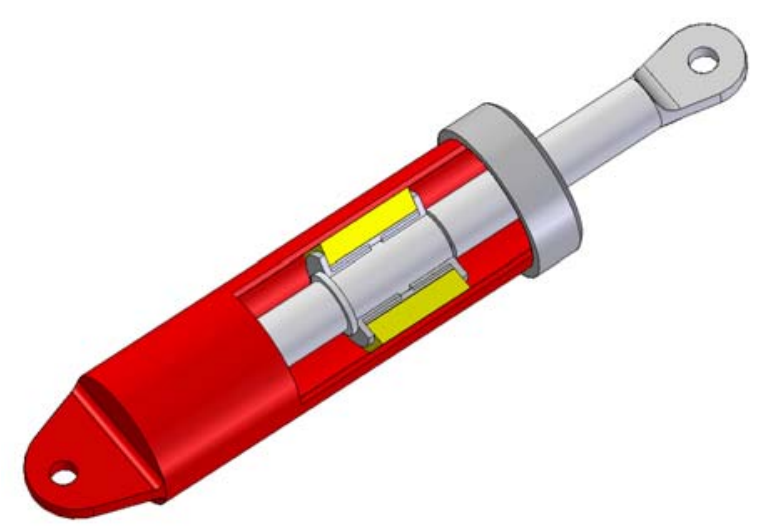

Fig. 2. Model of a damper with an elastometric sleeve.

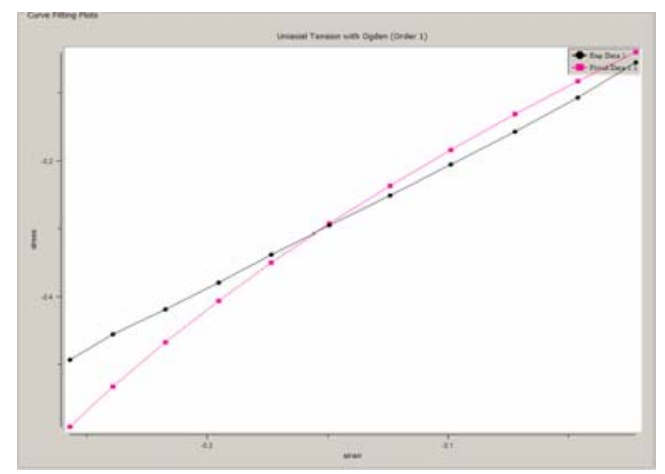

Fig. 3. Correspondence between the behavior of not proper model and experimental data.

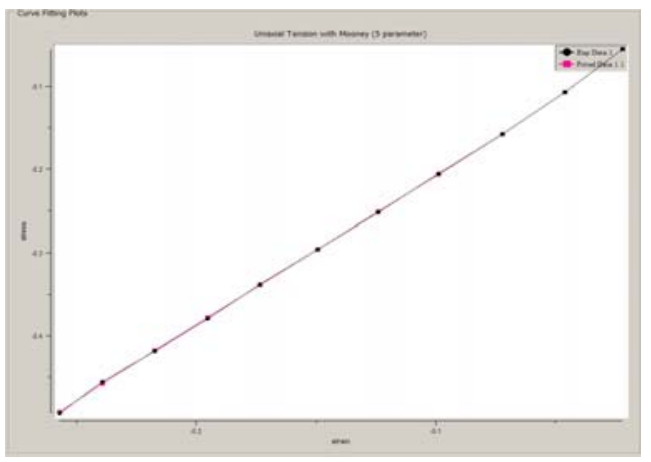

Fig. 4. Correspondence between the behavior of proper model and experimental data.

After choice of a mathematical model of material behavior, a FEM model has been build. Taking into consideration axial symmetric of sleeve, only $30^{\circ}$ piece has been build, simulating other part by boundary conditions. All the models were built using hexagonal elements, which give better accuracy. Because of simple geometry there was no reason to use more then 2000 elements. Every calculation was made when inner surface of sleeve was fixed. The contact pairs were used between sleeve and cylinder and between sleeve and resistance plates, when they were used. The friction coefficient was calculated using bisection method. All the calculations were made in two phases: first the interference were given, and then axial displacement.

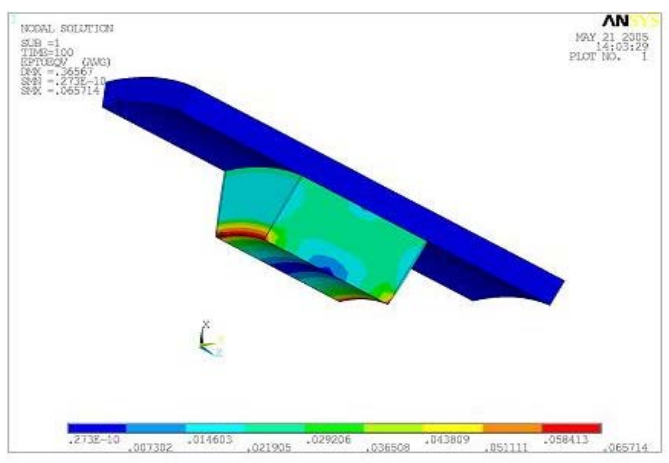

Fig.5. Numerical solution for elastometric sleeve by radial displacement. 


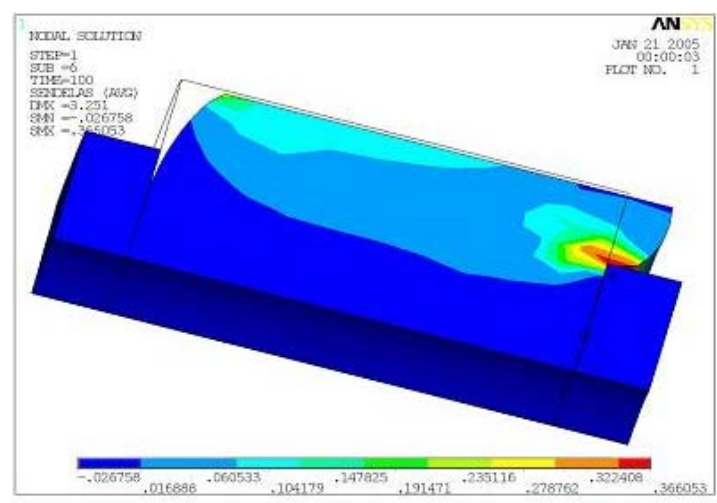

Fig. 6. Numerical solution for elastometric sleeve by radial and axial displacement.

\section{EXPERIMENTAL VERIFICATION}

All the tests and experiments were conducted in the Institute of Aviation in Warsaw. There were about 30 combinations of various materials, various interference and various resistance plates tested. The force on a rod was analyzed as a function of its displacement. The applied displacement was equal $\pm 12 \mathrm{~mm}$ by frequency 2Hz. The temperature and its influence were also measured.

The entire test confirmed calculations. On Fig. 7 there is a visible point between static and kinematical friction. Changing dimensions of the piston one can change the placement of the point. The differential coefficient of force curve may be changed using whether different material for the sleeve, or changing resistance plates.

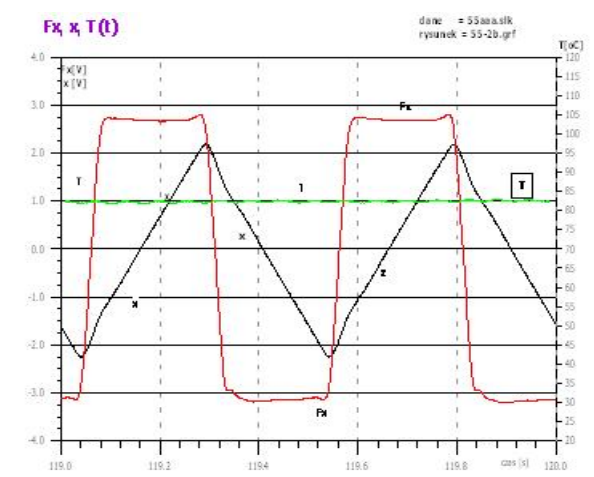

Fig.7. Example of an answer of a system.

\section{CONCLUSIONS}

All the experiments show that FEM calculations may be used for prediction of dimensions of sleeve, even when contact problems have to be considered. Furthermore, the simulated elasto-frictional forces calculated using Finite Element Method were measured also in real experiment. In the future the dynamic problems will be analyzed.

\section{REFERENCES}

Amborski J., Kajka R. - "Application of Finite Elements Method for Analysis and Design of Hyperelastic Material". ESM 2002 Conference, Darmstadt (Germany)

Amborski J. - „Modelowanie tłumików drgań z materiałem elastomerowym z zastosowaniem MES.” (Modeling vibration elastomer dampers using FEM), Doctor Thesis, Warszawa 2006

Osiński J., Amborski J. - "Elastomer Tests for finite Element Analysis Application", Proceedings of the XVI Polish-German Seminar, Development Trends in Design of Mechanics and Vehicles, Warszawa (Poland), June 2004, s. 103 - 110

Dacko A. - "Analysis of Elastometric Structural Components. 2000 - V KWPI Conference, Polanica Zdrój 2000 (Poland), s.253-262

Ogden R. W. - „Nonlinear Elasticity with Application to Material Modeling”, Institute of Fundamental Technological Research, Polish Academy of Sciences, Lecture Notes 6, Warszawa (Poland), 2003

Jaroszyńska D., Gaczyński R., Felczak B. - "Methods of Rubber's Physical Properties Tests", PWN Warsaw, Poland 1978

\section{AUTHOR BIOGRAPHY}

Jan AMBORSKI received M.Sc. in Aviation (1999) and Ph.D. in Mechanical Engineering (2006) from Warsaw University of Technology (Poland). In 1996 he studied at the University RWTH in Aachen (Germany), supported by DAAD. In 1999 he was the Captain of the Polish team - first European winning team in SAE Aero Design East Competition (Florida, USA). In 2000 he was supervisor of two Polish teams (both from Warsaw University of Technology) taking part in this competition. One of these teams won SAE Aero Design East 2000. Since 1999 he is a designer in the Institute of Aviation in Warsaw (Poland). 